\title{
Evaluation of biosecurity and fungal contaminants in the poultry farms in Songkhla Province, Thailand
}

\author{
Lakkhana Kanhayuwa Wingfield*, Apichaya Phaichamnan, Thavachinee Jumnongnit \\ Division of Biological Science, Faculty of Science, Prince of Songkla University, Songkhla 90110 Thailand \\ *Corresponding author, e-mail: Lakkhana.k@psu.ac.th
}

Received 30 Jan 2021

Accepted 25 Apr 2021

\begin{abstract}
Spreading of pathogenic fungi and toxigenic fungi in the poultry farms could lead to adverse health effects to exposed workers and chickens. Soil and air (indoor and outdoor) samples from two poultry farms in Songkhla Province, Thailand, were studied for the presence of fungal contaminants. The results demonstrated a mean value of $4445 \mathrm{CFU} / \mathrm{g}$ and $1908 \mathrm{CFU} / \mathrm{m}^{3}$ from soil and air samples, respectively. Statistical analysis revealed no influence of seasonal variation on the concentration of fungi. A total of 28 species belonging to 16 genera, including nonsporulating fungi, were recovered from soil and air samples in both poultry farms. Sixteen fungal genera were obtained in soil samples and Penicillium was the most frequently encountered genus (34.1\%), followed by Aspergillus (33.4\%) and Cladosporium (11.7\%). Ten genera (Aspergillus, Penicillium, Cladosporium, Fusarium, Curvularia, Trichoderma, Acremonium, Mucor, Rhizopus, and Scopulariopsis) were identified in the air samples. Characteristics of the poultry farms and surrounding environment were described and the biosecurity level of the farms was evaluated. The results revealed a low biosecurity level and high vulnerability to fungal contamination of the farms. The present study showed that poultry farms were potential reservoirs of substantial loads of fungal contaminants and fungal pathogens.
\end{abstract}

KEYWORDS: poultry farms, farm hygiene, biosafety and biosecurity risk, mycological contamination

\section{INTRODUCTION}

Soil represents the main habitat of fungi, while air represents the main reservoir of some airborne fungal pathogens. Fungi in the genera Stachybotry, Alternaria, Aspergillus, Cladosporium, Fusarium, Penicillium, Rhizopus, Mucor, Trichoderma, and Trichothecium. have been reported to be present in soil [1]. Some soil fungi are considered as potential pathogens to both humans and animals, particularly dermatophytic fungi which are commonly associated with human and animal mycoses $[2,3]$. Exposure to certain fungi could cause adverse health effects through three main approaches: (1) stimulation of a harmful immune response such as an allergic reaction or lung hypersensitivity, (2) direct infection by fungi, and (3) poisoning from mycotoxins [4]. To reduce the toxicity of mycotoxin, degraded products from biological manipulation have been described [5].

Small-scale poultry production systems have been integrated with Thais' livelihoods for centuries, enhancing income and food security of the locals, and are known as Thai indigenous chicken (TIC) production systems [6]. Most TIC farms accommodate large numbers of chickens in small areas, leading in high population density. Poor settings, poor management, and poor hygiene practices in poultry farms are usually encountered, rendering the farms significant sources of fungal contaminants and diseases. Contamination of fungal pathogens in soil and air may constitute a considerable health hazard to the chickens, farmers and those living in close proximity to the farms [1]. Airborne fungi and their mycotoxins carry an inherent of respiratory risk which has been linked to inhalation of fungal spores [7], thus they have received much attention from medical researchers as well as environmentalists. Airborne fungi are always present in the atmosphere, and their concentration varies depending on environmental conditions, fungal substrates, and human activities $[1,8]$. Exposure to organic dusts may activate asthma syndrome and chronic bronchitis. Inhalation of some fungal antigens and allergens may provoke immune responses and accelerate allergies. Poultry litter materials, such as wood chips, hay stalks, dried grass, rice straws, and rice hulls, have been reported as a major source of fungal contamination in poultry farms $[9,10]$. Generally, those litters are plowed into agricultural soil after being removed, leading to a potential harm to soil environment [3]. In addition, poor manure 
management practices also lead to soil and water pollutions.

Fungal diseases of poultry include aspergillosis, candidiasis, mucormycoses, mycotoxicoses, histoplasmosis, and cryptococcosis. Aspergillosis and mycotoxicosis are the most important diseases in the poultry production [11]. Fungal diseases in poultry farms usually arise sporadically, either from direct infection or production of mycotoxins. Prevention and control of fungal diseases are considerably difficult, and often result in economic losses to the poultry production. Therefore, effective prevention and control of such diseases are required, especially to control the concentration of fungal contaminants in the farms. In addition to health hazard to the chickens and farmers, reports on the occurrence and distribution of fungi and fungal contaminants in the poultry farms in Songkhla Province, Thailand are insufficient at present. Taking into consideration these concerns, the aim of this study was to identify the fungal community in the poultry farm soil and surrounding environment. Incidence of fungi according to seasonal variation was also analyzed to evaluate the extent and presence of fungi and fungal contaminants in these habitats. Moreover, the biosecurity level of the farms was evaluated to help assessing vulnerability of the farms to fungal and other microbial diseases.

\section{MATERIALS AND METHODS}

\section{Sampling sites}

Two poultry farms selected for the present study were located in Ban Dan Village $\left(7^{\circ} 6^{\prime} 1.6992^{\prime \prime} \mathrm{N}\right.$, $100^{\circ} 37^{\prime} 19.2504^{\prime \prime}$ E), Songkhla Province, Southern Thailand. Samples were assigned to seasons based on sampling dates (viz., hot season: February-May 2018, rainy season: June-October 2018, and cold season: November 2018-January 2019). During sampling, temperature (expressed in degrees Celsius), soil $\mathrm{pH}$, and relative humidity (expressed in percentage) were measured using portable devices. Data on location, ecology, climate, weather conditions, and other characteristics of the poultry farms were also taken.

\section{Biosecurity evaluation}

Farm biosecurity was evaluated using an adapted version of the simple biosecurity score form developed by Wei and Aengwanich [12] and in accordance with Biosecurity System of Food and Agriculture Organization of the United Nations (FAO) [13]. Observation of the farm management, farmers' prac- tices, and interviews were conducted. Scoring was divided into 4 levels: $0,1,2$, and 3. Evaluation was based on 14 factors applied in the Biosecurity score form. Data collection was done by observation of characteristics present in the farms and interview with farm workers for relevant information.

\section{Soil sample collection}

Eight fresh indoor soil samples were collected in sterilized bags. Each soil sample (10 g) was diluted in $90 \mathrm{ml}$ sterilized distilled water, then agitated for $30 \mathrm{~min}$ at $200 \mathrm{rpm}$. The samples were diluted from $10^{-1}$ to $10^{-8}$. A volume of $0.1 \mathrm{ml}$ the liquid sample was spread onto potato dextrose agar (PDA) supplemented with chloramphenicol $(50 \mu \mathrm{g} / \mathrm{ml})$ in triplicate and incubated for $5-10$ days at $28^{\circ} \mathrm{C}$.

\section{Air sample collection}

Eight air samples (four from indoors and four from outdoors) were collected using the impaction method [14]. Air was drawn through a $0.8 \mu \mathrm{m}$ Millipore filter at a height of one meter with a flow rate of $140 \mathrm{l} / \mathrm{min}$ for $30 \mathrm{~min}$. The outdoor samples were collected about one meter away from the selected poultry farms and with no obstacles or disturbing activities. The filters were rinsed in sterile water. An aliquot of $0.1 \mathrm{ml}$ rinsed sterile water was spread onto PDA supplemented with chloramphenicol $(50 \mu \mathrm{g} / \mathrm{ml})$ in triplicate and incubated for 5-10 days at $28^{\circ} \mathrm{C}$.

\section{Sample and fungal analysis}

Quantitative analysis of the air samples and the soil samples were performed by counting the colony forming units of the three replicas per cubic meter of air $\left(\mathrm{CFU} / \mathrm{m}^{3}\right)$ and per gram of soil $(\mathrm{CFU} / \mathrm{g})$, respectively. For qualitative analysis, identification of the fungal isolates was performed by observing the macroscopic and microscopic morphology of the colony using lactophenol blue staining, and the observed morphological characteristics were compared with those listed in literatures and standard mycology manuals [15-19]. Fungi were identified based on colony appearance, growth, and microscopic characteristics of the spore and hyphae. Fungal isolates which had failed to sporulate on PDA for over 2 months were transferred to low nutrient media (e.g., water agar medium and half or $1 / 4$ strength PDA [20]) to induce sporulation.

Frequency distribution of the fungal isolates was statistically analyzed from the obtained soil and air data using the SPSS 20.0 software. Comparison between CFUs of indoor and outdoor fungi 
Table 1 Characteristics and environment description of the poultry farms.

\begin{tabular}{ll}
\hline \multicolumn{2}{c}{ Poultry farms } \\
\hline GPS Coordinates & $7^{\circ} 6^{\prime} 1.6992^{\prime \prime} \mathrm{N}$ \\
& $100^{\circ} 37^{\prime} 19.2504^{\prime \prime} \mathrm{E}$ \\
Temperature & $28^{\circ} \mathrm{C}$ \\
Soil temperature at $0 \mathrm{~cm}$ & $28.5^{\circ} \mathrm{C}$ \\
Humidity & $\mathrm{Rh}=76 \%$ \\
Wind speed & $6.60 \mathrm{~km} / \mathrm{h}$ \\
Rain & $218 \mathrm{~mm}$. \\
Soil pH & $6.8-8.3$ \\
\hline
\end{tabular}

over seasons was performed using 2-tailed, 2-way ANOVA. $p$-values lower than 0.05 were considered statistically significant.

\section{RESULTS}

\section{Poultry farm description}

\section{Characteristics of the poultry farms and surrounding environment}

The two selected poultry farms are located in Songkhla Province, Southern Thailand. Table 1 shows the characteristics and environment description of the sampling sites. The ecology and characteristics of the farms are shown in Fig. S1 (a-k). The average temperature of the farms throughout the year was $28^{\circ} \mathrm{C}$, while the average soil temperature at $0 \mathrm{~cm}$ was $28.5^{\circ} \mathrm{C}$. The total average rainfall was about $218 \mathrm{~mm}$ with $76 \%$ relative humidity and a wind speed of $6.60 \mathrm{~km} / \mathrm{h}$. The soil $\mathrm{pH}$ ranged between 6.8 and 8.3. Both farms were categorized as a small-scale system for egg production, and each farm accommodated about 800-900 hens. Hens were raised in houses and kept in battery-powered cages arranged in long rows and multiple tiers. A single house accommodated approximately 150 200 hens. The cages were made of metal wire mesh and housed 4 to 5 hens per cage (Fig. S1(c,d,i)). Rice straws were used as litter materials for young hens. The poultry houses, arranged in cluster, were built on the farmers' own land.

The farms were established near the road at a safe distance of $300 \mathrm{~m}$ away from the community. The poultry houses were rectangular with open ends and situated approximately $50 \mathrm{~m}$ away from the roads (Fig. S1b). Full grown rubber trees and some betel vines were present around the farms. The houses were open-sided, without walls or netting, and constructed with wood materials, which were difficult to clean and disinfect and allowed other animals and humans to easily enter (Fig. S1(f,j)).
The house floors were mostly ground and some cemented areas. Some houses had thatched roof of dried grass, and some were built with gypsum roofing materials. The drainage system was not correctly installed along both sides of the houses, leaving stagnant water around the facilities. Although open-sided houses provided natural ventilation, distance between houses was only 2 to $3 \mathrm{~m}$, which could neither provide good aeration, nor biosecurity.

\section{Poultry farm management}

The overall management of the farms was relatively poor. In term of hygiene practices, the farms were not equipped with a proper disinfection system to maintain personal hygiene and to prevent diseases at the farms. There was no storeroom for feedstocks. Feeds were procured in bags made of woven plastic and stacked on the ground in an open area about $3 \mathrm{~m}$ away from the main poultry house (Fig. S1(j,h)). Hence, they were not protected from moisture. The moist feeds promoted growth of fungi which would pose a serious health risk to the hens and farm workers. Contamination of mycotoxinproducing fungi in feeds was the most concern because it could contribute to illness and mortality of the hens. In addition, the feed-stocks were very accessible by other pests and animals.

Regular management of excrement was not well-operated in these farms. Urine and feces were excreted as combined manure and released to the floors underneath the cages. Over time, high soil nitrogen content and accumulation of dust and pathogenic fungi occurred. Dry manure was usually collected and used or sold as organic fertilizers. Waste litter materials were removed regularly and usually disposed by burning.

\section{Occupational health issues}

The interviews were conducted with 10 farm workers on illnesses related to occupational health issues. A few workers had experienced respiratory illness, cough, allergic reactions, and skin infections. However, there was no proof that any of these illnesses were linked to an exposure of the airborne fungi at the farms. Emergence of aspergillosis and mycotoxicosis has been suspected, as one worker reported some suspicious death in young chickens. However, in-depth investigation on causes of the workers' illnesses and the death in young chickens had never been conducted. 
Table 2 Scoring results of 14 factors for biosecurity evaluation (adapted from Wei and Aengwanich [12].

\begin{tabular}{|c|c|c|c|c|}
\hline & \multirow{2}{*}{ Factor } & \multicolumn{2}{|c|}{ Score } & \multirow{2}{*}{ Definition } \\
\hline & & Farm 1 & Farm 2 & \\
\hline 1 & Attractiveness to wild birds & 2 & 2 & Trees surrounding the farms but no pond \\
\hline 2 & Wild bird protection & 0 & 0 & The bird net is not efficacious at all \\
\hline 3 & Measures related to staff in the farms & 0 & 0 & Staffs in the farm work without any regulations \\
\hline 4 & Measures for incoming poultry & 0 & 0 & No measures taken \\
\hline 5 & Measures for visitors & 0 & 0 & Visitors can enter the poultry houses freely \\
\hline 6 & Measures for traders & 0 & 0 & No measures for the traders at all \\
\hline 7 & Measures for equipment and vehicles & 0 & 0 & No control to the vehicles \\
\hline 8 & Source and treatment of water & 2 & 2 & Water from healthy source, no pollution \\
\hline 9 & Source of feed & 3 & 3 & Feed provided by the company; no process is needed \\
\hline 10 & $\begin{array}{l}\text { Local environment: distance from roads } \\
\text { and other farms }\end{array}$ & 3 & 3 & $\begin{array}{l}\text { Fully protection of the farm; more than } 300 \mathrm{~m} \\
\text { far from a public road }\end{array}$ \\
\hline 11 & Types of poultry in the farm & 3 & 3 & Only one type of poultry \\
\hline 12 & Capacity to clean and disinfect the farm & 0 & 0 & No disinfection or cleaning at all \\
\hline 13 & $\begin{array}{l}\text { Measures taken at the entrance to } \\
\text { poultry houses }\end{array}$ & 0 & 0 & No disinfection or cleaning at all \\
\hline \multirow[t]{3}{*}{14} & Biosecurity plans & 1 & 1 & $\begin{array}{l}\text { Just obey any guidance or regulation of the local } \\
\text { authority. No particular plan }\end{array}$ \\
\hline & Biosecurity sector & $3 r d$ & 3rd & $\begin{array}{l}\text { Layers were raised in the opening houses constructed } \\
\text { without netting }\end{array}$ \\
\hline & Overall Score & 0 & 0 & Low biosecurity \\
\hline
\end{tabular}

\section{Evaluation of biosecurity of the poultry farms}

The results of biosecurity evaluation of the two poultry farms are presented in Table 2, and they showed that some essential biosecurity systems were not established in these farms. For example, there were no fences around the farm areas. Disinfectant pools for feet dipping and disinfectant spraying system for vehicles entering the farms were not available. According to the scoring results, the two selected poultry farms were categorized in the third security sector, which is signified as low biosecurity farming system where layers were raised in open houses constructed without netting [21]. The results also revealed that these types of farms were vulnerable to fungal contamination. Construction, characteristics, and management of the farms facilitated the spread of fungal diseases. In addition, workers tended to experience occupation-related illnesses caused by fungi.

\section{Fungal concentration in soil samples}

Mean value of fungal concentration in the indoor soil samples from both poultry farms was $4445 \mathrm{CFU} / \mathrm{g}$ (Table 3). According to statistical analysis, the soil fungal concentrations were similar regardless of seasons. The highest concentration of indoor soil fungi was recorded in the summer
Table 3 Seasonal variations of the fungal soil and air concentrations in the two poultry farms.

\begin{tabular}{lclccc}
\hline \multirow{2}{*}{ Sample } & \multirow{2}{*}{ Site } & Season & \multicolumn{2}{c}{ Poultry farm } & Overall \\
\cline { 3 - 4 } & & & 1 & 2 & mean \\
\hline Soil & Indoor soil & Summer & 5850 & 3512 & $4681^{\mathrm{a}}$ \\
& $(\mathrm{CFU} / \mathrm{g})^{\dagger}$ & Rainy & 4908 & 3408 & $4158^{\mathrm{a}}$ \\
& & Cold & 5186 & 3808 & $4497^{\mathrm{a}}$ \\
\hline Air & Indoor air & Summer & 3169 & 2193 & $2681^{\mathrm{b}}$ \\
& $\left(\mathrm{CFU} / \mathrm{m}^{3}\right)^{\dagger}$ & Rainy & 2672 & 1644 & $2158^{\mathrm{b}}$ \\
& & Cold & 2951 & 2043 & $2497^{\mathrm{b}}$ \\
\cline { 3 - 5 } & & & & \\
& Outdoor air & Summer & 1882 & 1304 & $1593^{\mathrm{c}}$ \\
& $\left(\mathrm{CFU} / \mathrm{m}^{3}\right)^{\dagger}$ & Rainy & 1238 & 1180 & $1209^{\mathrm{c}}$ \\
& & Cold & 1392 & 1228 & $1310^{\mathrm{c}}$ \\
\hline
\end{tabular}

$\dagger$ The results were presented as the mean values of three replicas. Different letters indicate significant differences according to a Duncan's multiple range test $(p<0.05)$.

season at $4681 \mathrm{CFU} / \mathrm{g}$, followed by $4497 \mathrm{CFU} / \mathrm{g}$ in the cold season and $4158 \mathrm{CFU} / \mathrm{g}$ in the rainy season. Twenty-eight fungal species belonging to 16 genera were recovered from the soil samples, and the most frequent genus was Penicillium (34.1\%) (Table 4). The total number of representing fungal species found in the indoor soil were: Penicillium $=3$ (34.1\%), Aspergillus spp. $=9$ (33.4\%), Cla- 
Table 4 Most frequent fungi detected in soil samples and indoor and outdoor air samples in both poultry farms.

\begin{tabular}{|c|c|c|c|c|}
\hline \multirow{2}{*}{ Fungi } & \multicolumn{4}{|c|}{ Frequency (\%) } \\
\hline & $\begin{array}{c}\text { Soil } \\
\text { (total) }\end{array}$ & $\begin{array}{c}\text { Indoor } \\
\text { air }\end{array}$ & $\begin{array}{l}\text { Outdoor } \\
\text { air }\end{array}$ & $\underset{\text { (total) }}{\text { Air }}$ \\
\hline Absidia sp. & 0.3 & - & - & - \\
\hline Acremonium sp. & 1.4 & 3.4 & 2.4 & 2.9 \\
\hline Alternaria alternata & 0.5 & - & - & - \\
\hline Aspergillus spp. & 11.5 & 2.4 & 5.9 & 4.2 \\
\hline A. candidus & 0.1 & - & - & - \\
\hline A. clavatus & 0.5 & - & - & - \\
\hline A. flavus & 4.8 & 11.7 & 18.4 & 15.1 \\
\hline A. fumigatus & 3.9 & 14.4 & 23.2 & 18.8 \\
\hline A. niger & 6.1 & 15.5 & 11.5 & 13.5 \\
\hline A. ochraceus & 0.4 & - & - & - \\
\hline A. oryzae & 1.5 & 2.9 & 1.7 & 2.3 \\
\hline A. tamarii & 0.3 & - & - & - \\
\hline A. terreus & 4.3 & 3.4 & 1.9 & 2.7 \\
\hline Cladosporium spp. & 5.4 & 0.8 & 1.2 & 1.0 \\
\hline C. cladosporioides & 5.0 & 3.0 & 2.6 & 2.8 \\
\hline C. herbarium & 1.3 & 1.5 & 1.4 & 1.5 \\
\hline Curvularia lunata & 1.2 & 1.2 & 1.7 & 1.5 \\
\hline Exophiala sp. & 0.2 & - & - & - \\
\hline Fusarium spp. & 1.1 & 0.1 & 0.1 & 0.1 \\
\hline F. oxysporum & 2.4 & 0.8 & 1.1 & 1.0 \\
\hline F. solani & 1.1 & 0.5 & 0.9 & 0.7 \\
\hline Microsporum gypseum & 2.3 & - & - & - \\
\hline Mucor sp. & 0.7 & 1.1 & 2.9 & 2.0 \\
\hline Paecilomyces sp. & 1.3 & - & - & - \\
\hline Penicillium spp. & 16.8 & 12.4 & 8.9 & 10.7 \\
\hline$P$ citrinum & 2.1 & 0.7 & 0.3 & 0.5 \\
\hline P. nigricans & 3.7 & 1.7 & 0.4 & 1.1 \\
\hline P. versicolor & 11.5 & 8.3 & 0.8 & 4.6 \\
\hline Rhizopus sp. & 1.2 & 3.2 & 3.5 & 3.4 \\
\hline Scopulariopsis sp. & 1.1 & 5.8 & 5.2 & 5.5 \\
\hline Trichoderma viride & 0.6 & 1.9 & 1.7 & 1.8 \\
\hline Trichophyton mentagrophytes & 1.6 & - & - & - \\
\hline Non-sporulating fungi & 3.8 & 3.3 & 2.3 & 2.8 \\
\hline Number of genera & 16 & 10 & 10 & 10 \\
\hline Number of species & 28 & 18 & 18 & 18 \\
\hline
\end{tabular}

dosporium $=2(11.7 \%)$, Fusarium $=2(4.6 \%)$, Alternaria $=1(0.5 \%)$, Curvularia $=1(1.2 \%)$, and Trichoderma $=1(0.6 \%)$. Other fungal species were also found: Absidia sp. (0.3\%), Acremonium sp. (1.4\%), Exophiala sp. (0.2\%), Mucor sp. (0.7\%), Paecilomyces sp. (1.3\%), Rhizopus sp. (1.2\%), Scopulariopsis sp. (1.1\%), and non-sporulating fungi (3.8\%). In addition, two dermatophytic fungi, Microsporum gypseum and Trichophyton sp., were detected and comprised 3.9\%.

\section{Fungal concentration in air samples}

Mean value of the fungal concentration in the air samples, indoor and outdoor, from both poultry farms was $1908 \mathrm{CFU} / \mathrm{m}^{3}$, of which the indoor and the outdoor values were $2445 \mathrm{CFU} / \mathrm{m}^{3}$ and $1371 \mathrm{CFU} / \mathrm{m}^{3}$, respectively (Table 3). The indoor air fungal concentrations of both farms were higher than the respective outdoor values. According to statistical analysis, the fungal concentrations in both indoor and outdoor air samples were similar re-

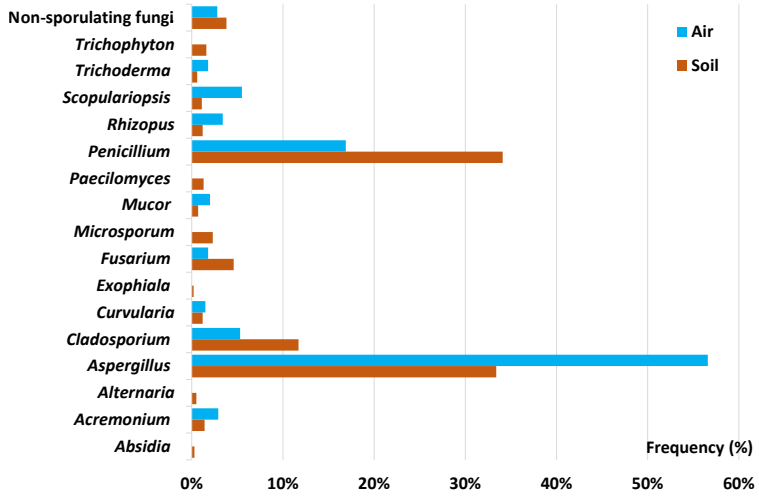

Fig. 1 Distribution of fungi in soil and air samples.

gardless of seasons. For the indoor air, the highest concentration of fungi of $2681 \mathrm{CFU} / \mathrm{m}^{3}$ was recorded in the summer season, followed by the cold season and the rainy season of $2497 \mathrm{CFU} / \mathrm{m}^{3}$ and $2158 \mathrm{CFU} / \mathrm{m}^{3}$, respectively. As for the outdoor air, the highest fungal concentration was also found in the summer season followed by the cold and the rainy seasons with the values of $1593 \mathrm{CFU} / \mathrm{m}^{3}$, $1310 \mathrm{CFU} / \mathrm{m}^{3}$, and $1209 \mathrm{CFU} / \mathrm{m}^{3}$, respectively.

Based on comparative analysis, both the indoor and outdoor air samples showed the same data on types of fungi detected in the two farms, 18 species belonging to 10 genera; and the most frequent genus was Aspergillus with $50.3 \%$ in the indoor air and $62.6 \%$ in the outdoor air (Table 4). The results in Table 4 also indicated that genera and species of all the fungi cultured from the indoor and outdoor air samples of the two farms were not different. However, variation in percentage of incidence was found between the indoor and outdoor environments.

The overall fungal genera and their total proportions in the soil and the air samples are demonstrated in Fig. 1, which presented different incidences of fungal community in the two habitats. Examples of fungal diversity found in the soil and the air samples in the poultry farms are shown in Figs. 2 and 3.

\section{DISCUSSION}

Fungal pathogens are a significant economic concern to the poultry production system. The main source of poultry pathogens is the mixture of house materials, chicken excrement, feathers, and the surrounding environment [22]. Fungi and their metabolites (e.g., volatile organic compounds (VOCs) and mycotoxins) may cause occupational 


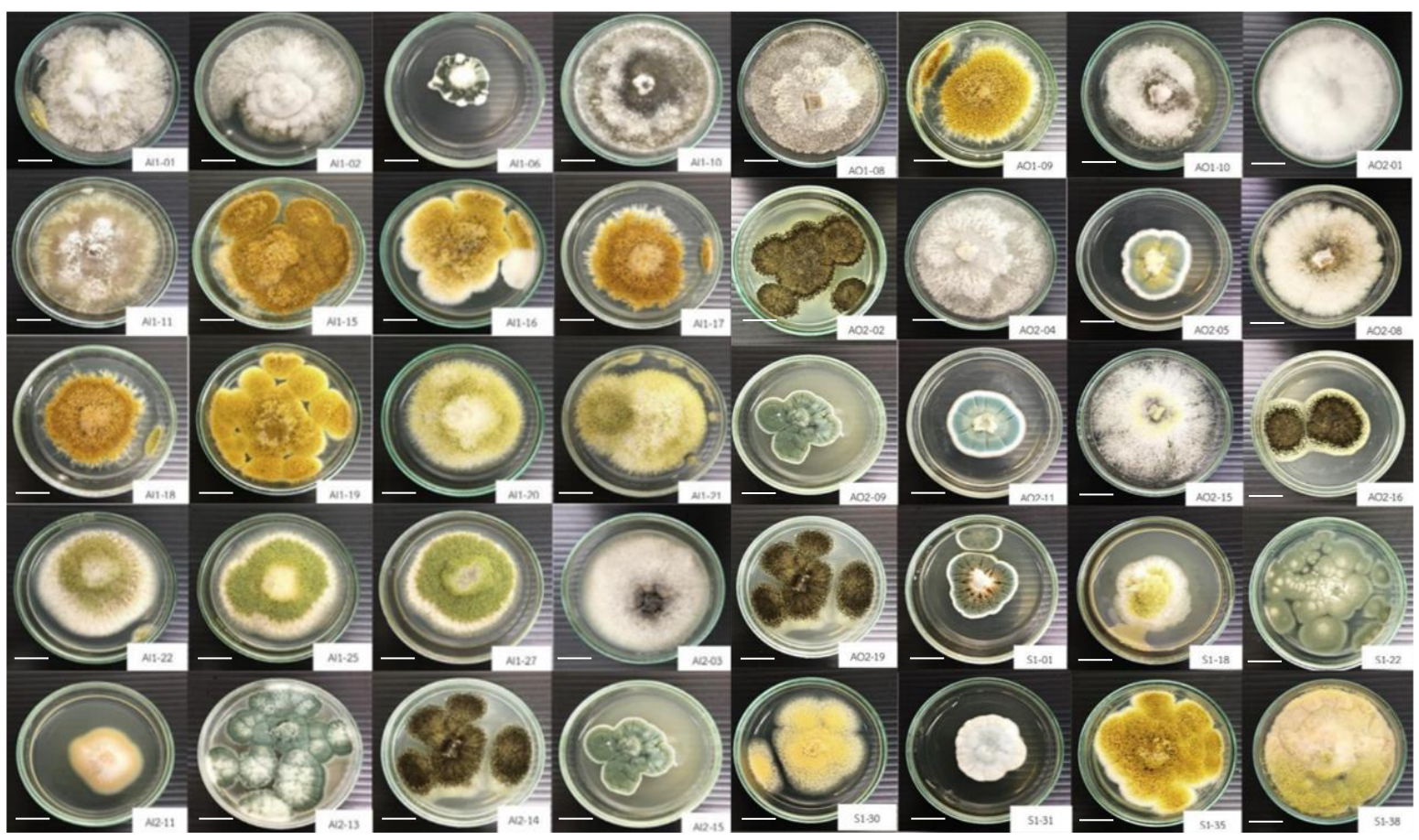

Fig. 2 Examples of fungal diversity found in soil and air samples. Scale bar $=1 \mathrm{~cm}$.

and public health risks to workers and animals in poultry houses. Two poultry farms selected for the present study were investigated for the incidence of fungal contamination in farm sites. The fungal community was investigated from soil and air samples and analyzed for seasonal variations to evaluate the extent and presence of fungi in each season. Prior to the study on fungal contamination in these habitats, characteristics of the poultry farms and surrounding environment were observed. Likewise, the biosecurity level of the farms was evaluated to assess the vulnerability of the farms to fungal and other microbial diseases.

From the investigation, the farms were categorized as a small-scale poultry production system for egg production. Observation on house construction, layers' density, surrounding environment, and overall farm management demonstrated that these poultry farms do not strongly comply with the standard regulation for Good Agricultural Practice (GAP) and Livestock Farm Standards (LFS) set by the Bureau of Livestock Standards and Certification, Department of Livestock Development (DLD, Ministry of Agriculture and Cooperatives, Bangkok, Thailand). Biosecurity of the farms was also evaluated, which categorized the selected farms as the third security sector and signified as low biosecurity. Poor farm management is a predominant concern, followed by farm construction, hygiene practices, and worker routines. Ineffective feed storage system, poor waste and manure management, and lacking proper hygiene practices could result in the accumulation of the overall fungal concentration in the farm environment by increasing the volumes of fungal spores and organic residuals. The results also revealed that these farms appeared to be vulnerable to the contamination of fungal contaminants and the spread of fungal and other microbial diseases. It is evident that layer farms are more vulnerable to contamination and diseases than broiler farms [23]. Moreover, workers were prone to occupation-related illness caused by fungi in this type of poultry production system. Therefore, it is important to enhance the ability of farm workers and farm owners to recognize the significance of biosecurity measures.

Worldwide database on fungal contaminations in poultry houses and other environmental farming has been documented [8, 10,24-26]. According to those studies, the concentrations of soil fungi in animal houses range from $1.8 \times 10^{3}$ to $4.2 \times 10^{7} \mathrm{CFU} / \mathrm{g}$, while concentrations of airborne fungi range from $2.5 \times 10^{1}$ to $4.9 \times 10^{6} \mathrm{CFU} / \mathrm{m}^{3}$. In this study, a mean value of $4445 \mathrm{CFU} / \mathrm{g}$ was isolated from soil samples, whereas a mean value of $1908 \mathrm{CFU} / \mathrm{m}^{3}$ was isolated from air samples from both poultry farms, show- 


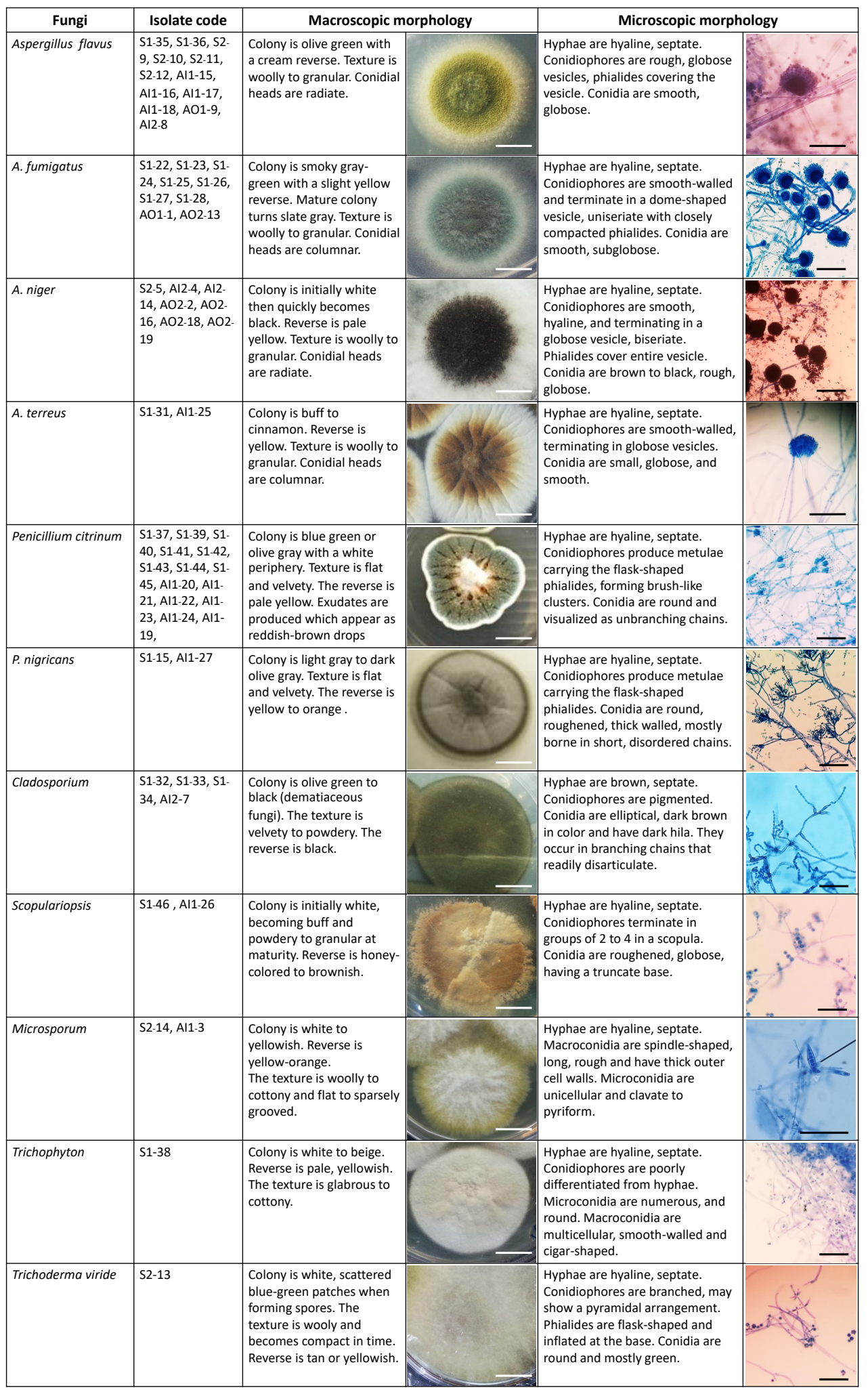

Fig. 3 Macroscopic and microscopic morphologies of the representative taxa found in the poultry farms. Fungal colony, scale bar $=1 \mathrm{~cm}$. Fungi under the microscope $(40 \times)$, scale bar $=40 \mu \mathrm{m}$. 
ing significant differences in fungal concentrations between the two habitats. Statistically significant differences were not found when comparing total fungal concentration $\left(\mathrm{CFU} / \mathrm{m}^{3}\right)$ between indoor and outdoor air. The highest level of fungal concentration in the air was found in the summer season followed by the cold and the rainy seasons. This could be attributed to temperature, abundance in dead plant materials, and other environmental factors that favor the growth and accumulation of fungi in the summer period. Although fungal concentration levels in the rainy season were decreased (possibly due to washing of fungal spores from the air), the seasonal occurrences of fungal concentration in soil and air were not significantly different according to the statistical analysis.

The selected farms presented a variety of fungal genera found in the soil and the air samples. They were Absidia, Acremonium, Alternaria, Aspergillus, Cladosporium, Curvularia, Exophiala, Fusarium, Microsporum, Mucor, Paecilomyces, Penicillium, Rhizopus, Scopulariopsis, Trichoderma, and Trichophyton. Similar soil and airborne fungi have been recorded in the poultry and animal units $[3,8,10,27-29]$. It could be possible that relative humidity, indoor temperature, and hygiene conditions in the farms are factors that support the growth of fungi. Regarding fungal community present in the farm environment, the three most prevalent genera in the soil samples in descending order were Penicillium, Aspergillus, and Cladosporium. Among the fungi found in the soil samples, some potential pathogenic fungi were recovered. A. fumigatus, which causes serious diseases in humans and animals [30]; and A. flavus, which is a well-known producer of potent mycotoxins, were the most frequently isolated species among the Aspergillus. The finding was consistent with the results reported by Hubalek et al [27] and Anbu et al [3] reporting the occurrence of these species from bird feature and poultry dumping soil. Kotimaa et al [28] also noted Aspergillus, Penicillium, and Cladosporium as the most frequently isolated genera found in feeding and bedding materials. In addition, Absidia and Exophiala responsible for human and animal mycoses were detected but in a very low frequency. Meanwhile, the dermatophytes and the keratinophilic fungi, Microsporum, Scopulariopsis, and Trichophyton, the main causative agents for cutaneous mycoses, were also detected in the soil samples from the poultry farms. The occurrence of these genera was also reported by Anbu et al [3], Mini et al [29], and Viegas et al [8].

Regarding air samples, the present study demonstrated that the fungal concentration of the indoor air samples was higher than that of the outside air samples in both poultry farms. The concentration of indoor fungi can be two to five times higher than that of the outdoor fungi [31]. Indoor fungal concentration possibly led to the contamination of fungi in the outdoor environments since the presence of fungal community was relatively similar. Furthermore, our results showed that the three most prevalent genera in the air samples in descending order were Aspergillus, Penicillium, and Scopulariopsis. Concerning the Aspergillus genus, different species were isolated from both indoors and outdoors. Some of which are described as causative agents for respiratory infections in lungs, such as A. fumigatus and A. flavus. Spreading of the genus in the poultry farm air environment could be attributed to aerosolization of fungal spores present in the soil. It was convincible that occupants, number of chickens, and activities carried out in the farms may affect aerosolization and make the fungi become airborne [32,33]. Inhalation of fungal spores contaminated in the animal farms is usually associated with development of respiratory symptoms, such as hypersensitivity pneumonitis and asthma, which are harmful to farm workers [34]. The discovery of Scopulariopsis in the air samples needs to be considered with caution, since exposure to this fungal genus is associated with occupational allergy in some cases [35].

\section{CONCLUSION}

The present study revealed that poultry farms were potential reservoirs of substantial concentrations of fungi and fungal contaminants. Evaluation on biosecurity and vulnerability revealed that these poultry farms were categorized as low biosecurity level and did not comply with regulatory standards, making the farms vulnerable to the contamination of fungal contaminants. These results suggest that biosecurity practices of the farms need urgent improvement. Environmental modification, as well as appropriate control strategies, should be implemented to decrease exposure to fungal spores and to control the spread of mycoses. Comparison of fungal concentrations between soil and air samples demonstrated significant differences in fungal loads. However, fungal communities were relatively similar. Seasonal variation did not affect fungal concentrations in both habitats. The findings revealed that, in descending order, Penicillium, Aspergillus, and Cladosporium were the most prevalent genera in the soil samples, whereas Aspergillus, Penicillium, 
and Scopulariopsis were the most prevalent genera in the air samples. Some potential pathogenic fungi were recovered in the farms, which may pose occupational and public health risks to farm workers and animals.

\section{Appendix A. Supplementary data}

Supplementary data associated with this article can be found at http://dx.doi.org/10.2306/ scienceasia1513-1874.2021.058

Acknowledgements: This work was supported by the New Researcher Grants sponsored by Ministry of Science \& Technology, National Science and Technology Development Agency (NSTDA), Thailand for Lakkhana Kanhayuwa Wingfield.

\section{REFERENCES}

1. Lonc E, Plewa K (2011) Comparison of indoor and outdoor bioaerosols in poultry farming. In: Moldoveanu A (ed) Advanced Topics in Environmental Health and Air Pollution Case Studies, IntechOpen, Rijeka, pp 339-352.

2. Papini R, Mancianti F, Grassotti G, Cardini G (1998) Survey of keratinophilic fungi isolated from city park soils of Pisa, Italy. Mycopathologia 143, 17-23.

3. Anbu P, Hilda A, Gopinath S (2004) Keratinophilic fungi of poultry farm and feather dumping soil in Tamil Nadu, India. Mycopathologia 158, 303-309.

4. Bush R, Portnoy J, Saxon A, Terr A, Wood R (2006) The medical effects of mold exposure. $J$ Allergy Clin Immunol 17, 326-333.

5. Ernuo T, Xin D, Wenhao C, Changgao W, Jianguo L, Cai J (2020) Structure and toxicity analysis of aflatoxin $\mathrm{B}_{1}$ biodegraded products by culture supernatant of Cladosporium uredinicola. ScienceAsia 46, 308-314.

6. Choprakarn K, Wongpichet K (2008) Village chicken production systems in Thailand. In: Thieme O, Pilling D (eds) Poultry in the 21st Century: Avian Influenza and Beyond, Proceedings of the International Poultry Conference, Bangkok, pp 5-7.

7. Kirkhorn S, Garry V (2000) Agricultural lung diseases. Environ Health Perspect 108, 50-54.

8. Pavan R, Manjunath K (2014) Qualitative analysis of indoor and outdoor fungi in cowshed. $J$ Mycol 2014, ID 985921.

9. Williams CM (2010) Poultry waste management in developing countries. In: Poultry Development Review, FAO, Roma, Italy.

10. Viegas C, Carolino E, Malta-Vacas J, Sabino R, Viegas $S$, Veríssimo C (2012) Fungal contamination of poultry litter: A public health problem. $J$ Toxicol Environ 75, 22-23.

11. Asfaw M, Dawi D (2017) Review on major fungal disease of poultry. Br Poult Sci 6, 16-25.
12. Wei H, Aengwanich W (2012). Biosecurity evaluation of poultry production cluster. Int $J$ Poult Sci 11, 482-588.

13. FAO (2008) Biosecurity for Highly Pathogenic Avian Influenza: Issue and Options, FAO, Rome, Italy.

14. Hendrick D, Brouwer R, Biersteker H, Boleij JSM (1991) Relationship of airborne endotoxin and bacteria levels in pig farms with the lung function and respiratory symptoms of farmers. Inter Ach Environ Health 62, 595-601.

15. Wolf PL, Russel B, Shimoda A (1975) Practical Clinical Microbiology and Mycology: Technique and Interpretation, John Wiley and Sons, New York, USA.

16. Onion AHS, Ilsopp D, Eggins HOW (1981) Introduction to Mycology, Edward Arnold Publishers, London.

17. Hoog C, Guarro J, Gené G, Figueiras M (2000) Atlas of Clinical Fungi, 2nd edn, Centraal Bureauvoor Schimmelcultures, Utrecht, the Netherlands.

18. Dugan FM (2015) The Identification of Fungi: An Illustrated Introduction with Keys, Glossary, and Guide to Literature, The American Phytopathological Society Press, St. Paul, USA.

19. Ellis D, Davis S, Alexiou H, Handke R, Bartley R (2016) Description of Medical Fungi, 3rd edn, South Australia Nexus Print Solutions, Australia.

20. Su YY, Qi YL, Cai L (2012) Induction of sporulation in plant pathogenic fungi. Mycology 3, 195-200.

21. Tiensin T, Mielen M, Songserm T, Kalpravidh W, Chaitaweesub P, Amonsin A, Chotiprasatintara S, Chaisingh A, et al (2007) Geographic and temporal distribution of highly pathogenic avian influenza A virus in Thailand, 2004-2005: An overview. Avian Dis 51, 182-188.

22. Dumas M, Polson S, Ritter D, Ravel J, Gelb J, Morgan R, Wommack, K (2011) Impacts of poultry house environment on poultry litter bacterial community composition. PLoS One 6, ID e24785.

23. Souris M, Selenic D, Khaklang S, Ninphanomchai S, Minet G, Gonzalez JP, Kittayapong P (2014) Poultry farm vulnerability and risk of avian influenza reemergence in Thailand. Int J Environ Res Public Health 11, 934-951.

24. Radon K, Danuser B, Iversen M, Monso E, Weber CH, Hartung J, Palmgren U, Nowak D (2002) Air contaminants in different European farming environments. Ann Agric Environ Med 9, 41-48.

25. Northcutt J, Jones D, Musgrove M (2004) Airborne microorganisms during the commercial production and processing of Japanese quail. Int $J$ Pol Sci 3, 242-247.

26. Okiki PA, Ogbimi AO (2011) Microfungi and mycotoxins in poultry dust. Estud Biol 33, 81-86.

27. Hubalek Z, Balat F, Touskova I, Vik J (1973) Mycoflora of bird nests in nest-boxes. Mycopathol Mycol Appl 49, 1-12.

28. Kotimaa M, Oksanen L, Koskela P (1991) Feeding and bedding materials as sources of microbial expo- 
sure on dairy farms. Scand J Work Environ Health 17, 111-122.

29. Mini KD, Paul MK, Mathew J (2012) Screening of fungi isolated from poultry farm soil for keratinolytic activity. Adv Appl Sci Res 3, 2073-2077.

30. Ostro B, Lipsett M, Mann J, Braxton-Owens H, White M (2001) Air pollution and exacerbation of asthma in African-American children in Los Angeles. Epidemiology 12, 200-208.

31. US EPA Green Building Workgroup (2004) Buildings and the Environment: A Statistical Summary. US EPA Report, USA.

32. Milner P (2009) Bioaerosols associated with animal production operations. Bioresour Technol 100
5379-5385.

33. Tsapko V, Chudnovets A, Sterenbogen M, Papach V, Dutkiewicz J, Skórska C, Krysinska-Traczyk E, Golec M (2011) Exposure to bioaerosols in the selected agricultural facilities of the Ukraine and Poland: A review. Ann Agric Environ Med 18, 19-27.

34. Rylander R, Carvalheiro M (2006) Airways inflammation among workers in poultry houses. Int Arch Occup Environ Health 79, 487-490.

35. Ponikau J, Sherris D, Kern E, Homburger H, Frigas E, Gaffey T, Roberts G (1999) The diagnosis and incidence of allergic fungal sinusitis. Mayo Clin Proc 74, 877-884. 
Appendix A. Supplementary data
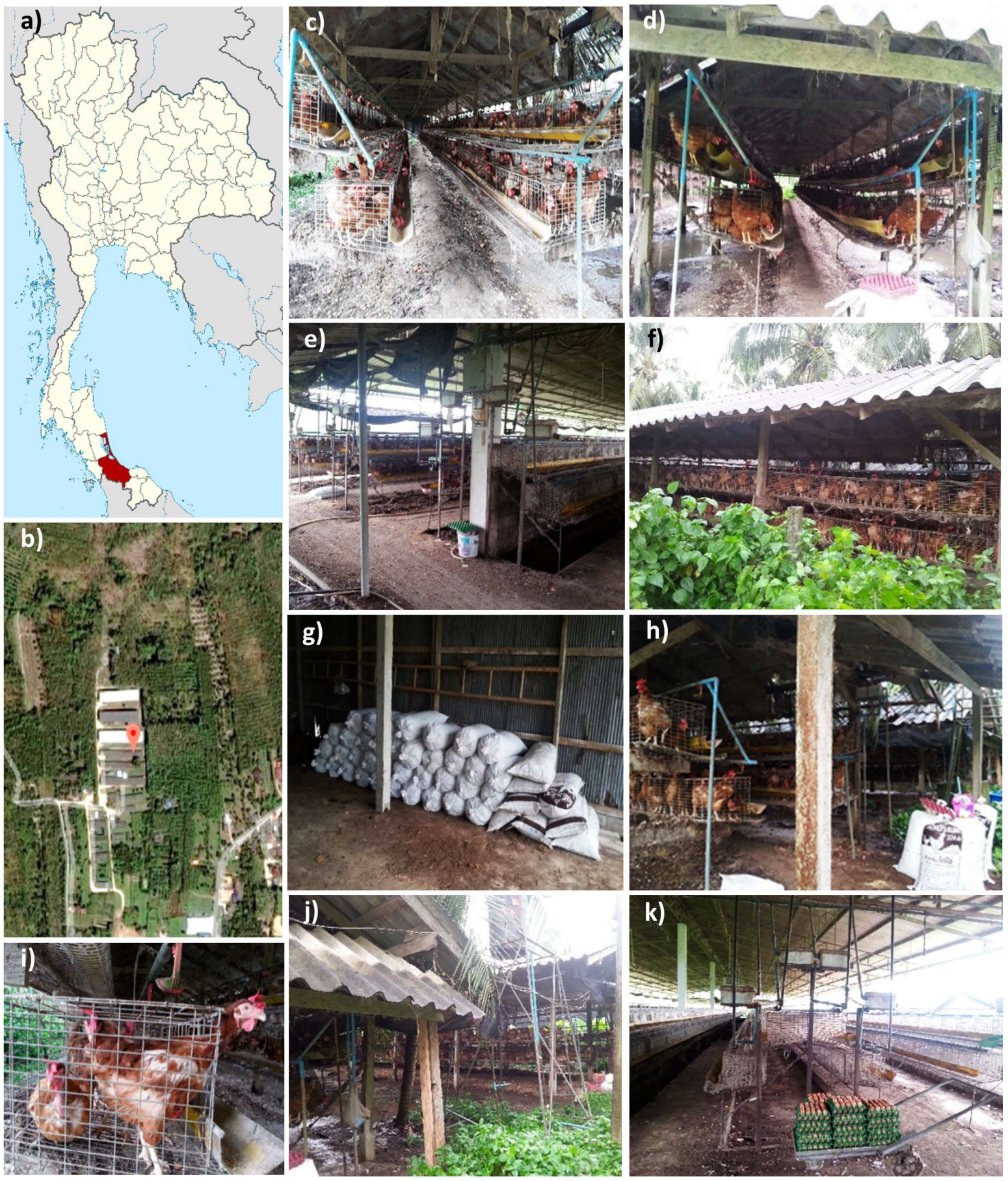

Fig. S1 Location, ecology, and characteristics of the selected poultry farms. 